\title{
How to Motivate External Open Innovation-Partners: Identifying Suitable Measures
}

\author{
Maik Holle, Luisa Elsesser, Matthias Schuhmacher, Udo Lindemann \\ Institute of Product Development, Technical University of Munich, Garching, Germany
}

\begin{abstract}
Shorter product life cycles require shorter innovation cycles which forces companies to launch new innovative products on the market at increasingly shorter intervals to stay competitive. A promising approach to face this challenge is described as the new paradigm of Open Innovation (OI) where knowledge of external partners (e.g. suppliers, product users or universities) is used to accelerate the company internal innovation process. Thereby, the motivation of external partners is, among other things, crucial for the success of an OIcollaboration. So far there is no systematic approach available in literature that provides guidance for finding the right "levers" to motivate these external partners to contribute their knowledge within an OI-collaboration. For this purpose, the present paper provides a methodology for identifying appropriate measures to motivate external partners depending on the type of cooperation (e.g. Idea Platform, Lead-UserWorkshop or Cross-Industry Innovations). Based on existing models in the research field of motivation psychology, suitable motivational factors are derived and considered. Finally, an interactive software-tool for raising the usability of the methodology is introduced.
\end{abstract}

\section{INTRODUCTION}

\section{A. Initial Situation}

During recent years, innovations are increasingly gaining importance for companies and are one of the most critical challenges in order to ensure a competitive edge in the long run [11]. Reference [39] defines Innovation as “... the management of all the activities involved in the process of idea generation, technology development, manufacturing and marketing of a new (or improved) product or manufacturing process or equipment." ([39], p. 15). Shorter product life cycles require shorter innovation cycles and therefore new products have to be launched on the markets at increasingly shorter intervals in order to stay competitive. Companies basically have two options to come up with product innovations. They can either use their internal knowhow or open up their innovation process and include external partners such as suppliers, product users, competitors or service providers [9] - in the following referred to as Open Innovation-partners (OI-partners). Reference [8] has first introduced the concept of Open Innovation (OI). He describes OI as "the use of purposive inflows and outflows of knowledge to accelerate internal innovation, and expand the markets for external use of innovation, respectively" ([8], p. 2). In other words, the chances accompanied by OI are manifested by higher innovation capabilities of companies. The new paradigm of OI is changing the way of innovating as OIpartners are having a key role in the innovation process. Looking for new product ideas exclusively within the company's boundaries can cause a local search bias, meaning to have only a very limited view of potential solutions [15].
Thus, companies are aiming for external collaborations in order to raise the potential of coming up with new product ideas or solutions during the innovation process.

In this context, selecting suitable OI-partners and OImethods (see chapter II $-A$. Open Innovation Methods) is one of the major challenge ([19]; [24]). Against this background, [20] developed an approach which provides guidance for a systematic and successful planning of an OI-project, called Situative Open Innovation (SOI - see Fig. 1). Therefore, five phases have to be distinguished, from which the first four phases are considered as "rough" planning and the fifth as detailed planning. After doing a situation analysis and defining OI-objectives (phase 1), OI-partners and OI-methods are selected afterwards (phase 2 and 3). Before getting into the detailed planning, the management of the OI-project is considered before (phase 4). An essential aspect of the detailed planning process (phase 5) is the motivation of external OI-partners as it is crucial for the success of the entire OI-project. However, a systematic approach to identify suitable incentives is not provided yet. Therefore, the focus of this paper is to come up with an approach that provides guidance for finding the right "levers" to motivate OIpartners.

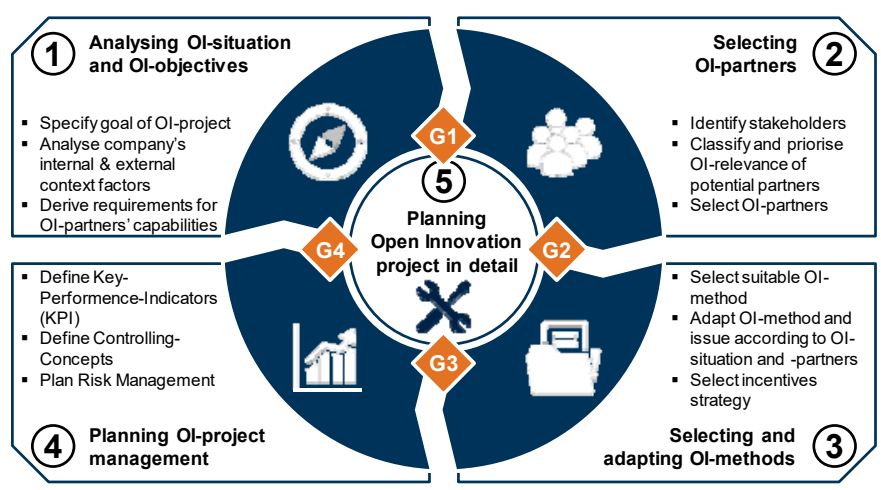

Fig. 1 Situative Open Innovation for systematically planning OI-projects [21]

\section{B. Problem and Research Questions}

Creating incentives for external OI-partners in order to motivate them to contribute their knowledge and experiences for solving technical problems or innovating products in general is crucial for the success of an OI-project. Thus, company's willing to open up their innovation process depends on external OI-partner's benevolence and motivation [13]. The question arises whether and how suitable incentives can be applied in order to ensure a successful participation of external OI-partners. So far there is no framework providing support for identifying and selecting appropriate incentives for a certain OI-project (mainly defined by OI-method to be 


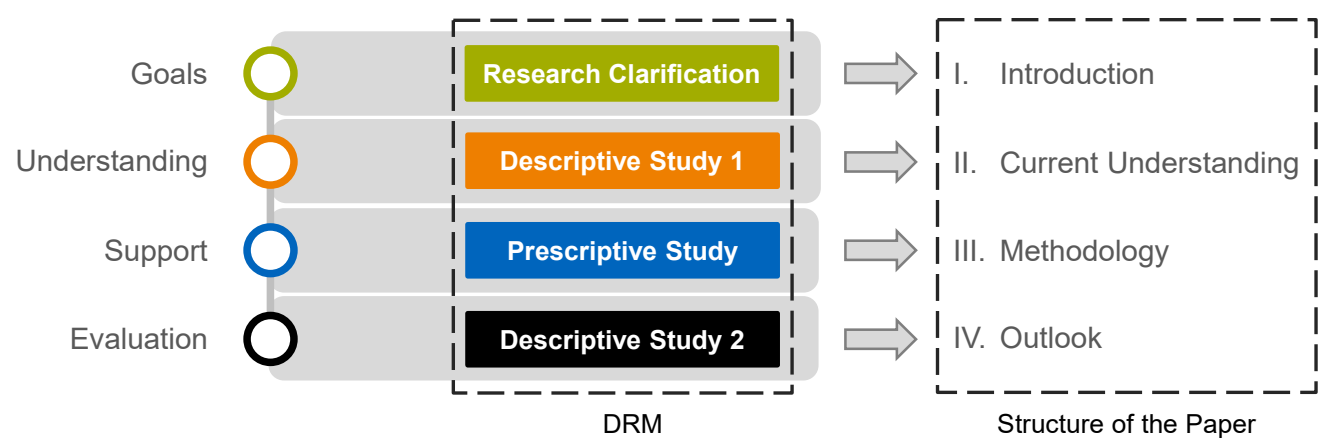

Fig. 2 Design Research Methodology (DRM) Framework [3] and resulting structure of the paper

conducted). Hence, the following research questions can be deduced:

1. How can external OI-partners be successfully motivated by applying approaches of motivation psychology?

2. How can the motivation of external OI-partners be supported by methods and tools?

\section{Research Design and Objective}

The scientific approach of this paper is based on the Design Research Methodology (DRM) according to [3]. The DRM framework is subdivided into different stages as depicted in Fig. 2.

For answering the research questions mentioned above, a methodology for identifying appropriate (with regard to a specific OI-project) measures to motivate external OI-partners (incentives) has to be developed in the course of the Prescriptive Study (see chapter III). The final objective is to provide an interactive software-tool in order to raise the usability of this methodology during the planning phase of an OI-project. In order to achieve this objective, the current state of the art (see chapter II) has to be taken as a basis and valuable approaches have to be transferred to the context of the planning of OI-projects. By doing so, relevant motivating factors have to be identified first. Based on this, requirements to indicate these motivational factors have to be derived and then be assessed regarding the general possibility to consider them within certain OI-methods (e.g. Idea Platform, Toolkits, Lead-User-Workshops - see chapter II “A. Open Innovation Methods"). Subsequently, suitable measures to fulfill derived requirements and therefore to motivate external OI-partners successfully, have to be defined. Finally, an evaluation of the presented methodology is suggested as Descriptive Study 2 (see chapter IV).

\section{CURRENT UNDERSTANDING (STATE OF THE ART)}

Before answering the research questions mentioned above, it is first of all necessary to give an overview about the existing OI-methods. The motivation should be based on existing models in the research field of motivation psychology, for what reason a summary of the most relevant concepts is provided as follows. The aim is to understand which factors are in general relevant for motivation. Based on that, important motivational factors are defined which have to be considered for a successful motivation of external OIpartners.

\section{A. Open Innovation Methods}

The research on OI diverges into different directions. Reference [27] and [10] are investigating on the degree of permeability from an internal and external point of view in order to find out the degree of opening up to the outside. Reference [7] evaluates the competencies required to introduce and implement the OI-approach. In research the direction of information flow across the company's boundaries is distinguished in three directions [40]:

- Inside-out process: Integration of external knowledge or experts.

- Outside-in process: External us of innovations and technologies, allotment of new markets.

- Coupled process: Cooperative innovation process with complementary partners in strategic alliance or network structure.

The direction to be considered in this paper is the outsidein process. Within the outside-in process, research is dealing with different OI-methodologies in order to find out how possible OI-collaborations and processes may look like ([5]; [14]; [35]). Making it more concrete, how collaboration can look like an overview of possible innovation methods is provided in the following:

- Idea Competition aim at generating as many ideas as possible within a certain time frame. Idea competitions can either be used in an early stage of an innovation process to get ideas how future products may look like or at a later stage in order to find innovative approaches for solving a technical problem ([35]; [37]).

- An Idea Platform is a web-based application which enables external OI-partners to introduce ideas to companies. Depending on the degree of interaction, external OI-partners are able to exchange knowledge on existing ideas and can cooperatively develop new ideas on this basis [35].

- Open Innovation Community represents an enhanced form of an Idea Platform by which companies are able to 
assess trends of the online community by letting the community evaluate the ideas itself.

- (Problem) Broadcasting is a related form of an Idea Competition. The difference to the aforementioned mostly lies in the smaller degree of interaction of participants (in this case also called OI-partners) who are not enabled to exchange their ideas. Their suggestions are directly delivered to the company. In addition, (Problem) Broadcasting is passively implemented, meaning that participants have to be selected by the company [25].

- Lead-User-Approach: Lead-Users are unsatisfied with certain aspects (e.g. functionality, design) of products which are already available on the market. They are seeking for new product solution and are therefore motivated as well as skilled at the same time to work on innovative solutions themselves [13].

- A Toolkit is understood as instruments enabling external OI-partners to define solution concepts according to their requirements [37]. Toolkits are web-based applications designed to establish interaction with various external OIpartners. By applying an iterative approach, external OIpartners create a solution according to their requirements within a virtual environment along with the given parameters. After finishing the solution idea they release the idea for the company in form of a virtual product model [35].

- Immersive Product Improvement (IPI) enables external OI-partners to directly report feedback on products via web-based functionalities. Therefore, a visualization of the respective product is provided. The external OI-partners can select one part of the product and leave their ideas for improvements, suggestions and requests as commentary. Other external OI-partners can access the feedback already provided and can, in turn, comment on it or leave other feedback [29].
- Netnography is a passive method not offering interaction with external OI-partners. It is a method enabling companies to register and analyze trends and customer requirements in online platforms, forums or communities by reading their comments and opinions. By analyzing data in the background, the company does not show to the public which issues and topics are investigated [2].

- Cross-industry Innovation is defined as transferring already existing solution ideas or concepts from other branches and markets to the internal problem case. The search for innovation is also extended to non-related companies [16].

- University Cooperation - with their research institutions and qualified scientists universities combine the required knowhow with the desired resources to be able to implement research work. Publicly promoted projects enabling the exchange of participating universities, are to be distinguished from cooperation of universities with individual companies [9].

\section{B. Model of Motivation}

The action of a human being is triggered by situational and individual variables. A model exemplifying this issue has been evaluated by [32] and is considered to be the Basic Model of Motivation Psychology.

As illustrated in Fig. 3, human motivation is influenced on the one hand by motives and on the other hand by external factors such as incentives [36]. Motives are individual preferences for certain incentives, vary from person to person and cannot be externally influenced [34]. This means, motives determine which incentives are perceived as attractive by a person, which, in turn, means that the incentives motivate persons differently [36]. Starting to understand individual's behavior, the Compensation Model of Motivation and Volition by [26] is explained. The model distinguishes implicit and explicit motivational factors as well as perceived abilities (see Fig. 4).

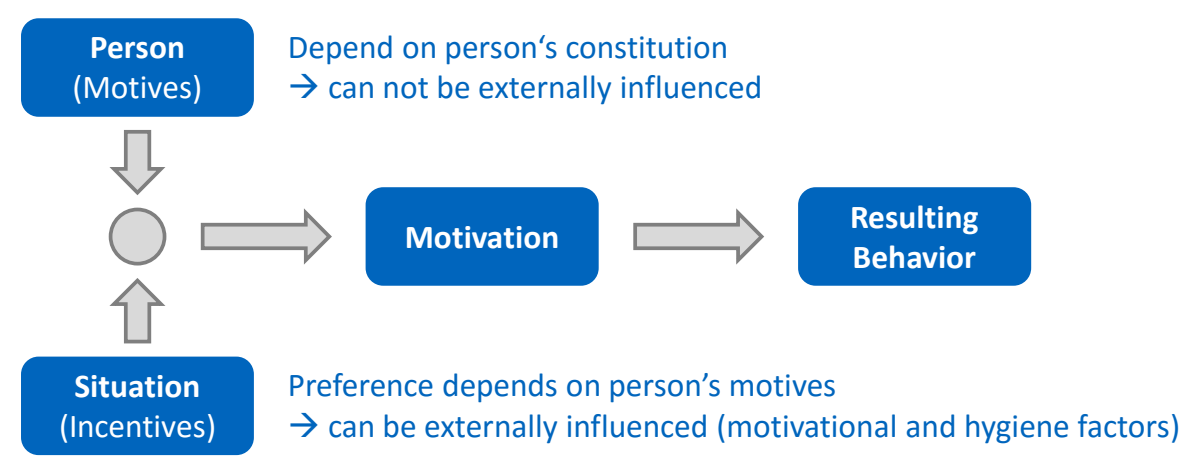

Fig. 3 Basic Model of Motivation Psychology (according to [32]) 


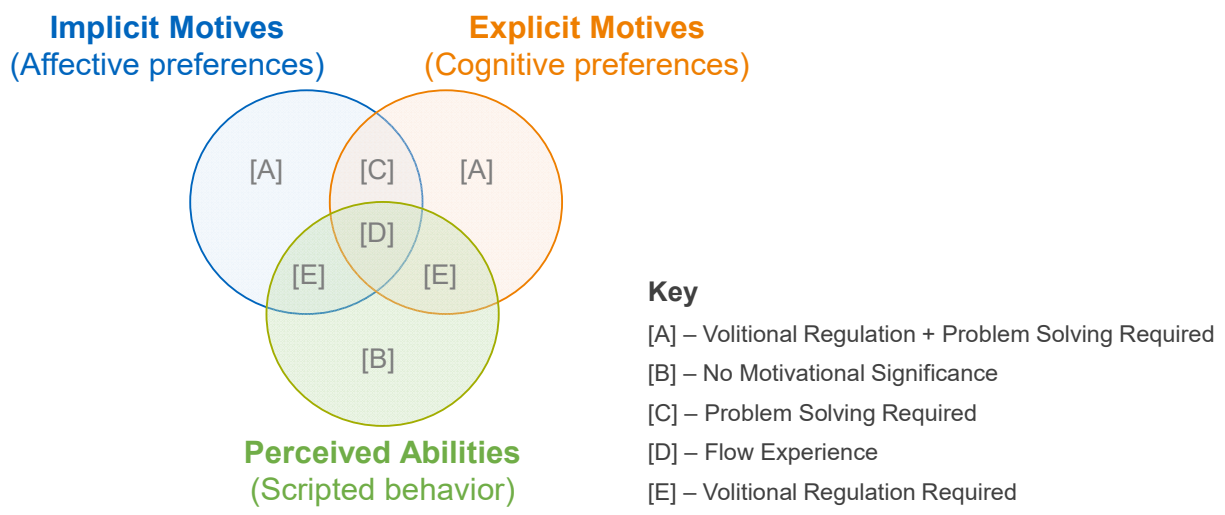

Fig. 4 Compensation Model of Motivation and Volition (according to [26])

According to [26] these three factors need to correspond to each other, because willing control is hard to maintain over a longer period of time. The consistency of these motives consequently leads to an increase in positive feelings in the course of the action and a flow experience (appears when the capabilities perfectly match the task and interests are implied [31]. Transferred to OI-projects this implies that any establishment of incentives might be superfluous, if a flow experience can be created for the external OI-partner. However, it is not possible to generate such an experience, if the factors are not all met [26]. Reference [34] defines three basic motives, which are relevant for an individual's behavior:

- Affiliation Motive describes the need for social contacts and feedback.

- Performance Motive describes the need of having a satisfying task, which is neither too easy nor too difficult.

- Power Motive describes the need for control above one's own situation and of others as well as the need for status.

Apart from the three basic motives described above, [22] are proposing to consider external and internal motivational factors, as this is supposed to have a promising outcome in terms of motivation [22]. For OI-projects this implies that not only the project itself needs to be considered while planning, but that the surrounding and personal attitudes also have a significant effect on the project's success [35]. Based on an approach of [34] and [22], the motivational factors are gathered likewise. Therefore, the motivation of external OIpartners, who have already been motivated to participate in OI-projects, provides the basis for the motivational factors for OI-projects in the following. Various authors come up with different motivational factors, which can be considered as factors why external OI-partners want to participate in an OIproject [36]:

- Enjoying the task: The task is perceived as a challenge and is satisfied while working on it. This phenomenon is strongly connected with flow experience [30].

- Flow Experience appears when the capabilities perfectly match the task and interests. If this state is reached, motivation will be maintained in the long-run [31].
- Team Objectives: External OI-partners are motivated if they can work together with other people [23].

- Self-Marketing as a motivational factor includes two considerations. First, increased reputation on the job market and second, social acceptance among a peer group ([8]; [18]).

- Self-Efficacy is the basis for having a flow experience. In other words, the difficulty of a task should fit one's capabilities in order to apply and extend the knowledge base ([23]; [36]).

- Direct compensation is the most used, motivational factor. The compensation is realized by giving money, vouchers or other advantages to external OI-partners ([22]; [6]; [1]).

- Expected Profit is especially important if external OIpartners with a similar knowledge base take part in a competition. The motivation to deliver high-quality suggestions is increased when OI-partners anticipate that they can win the challenge [42].

- Product required: The motivation is especially high if a product is required for satisfying customer's needs but not yet available on the market [33].

- Importance: The external OI-partner is considering his contribution to the project's success. If he feels like irreplaceable within the project, he feels motivated according to this fact [23].

- Technology Improvement: Driver for this motivational factor is the fact that an external OI-partner is seeking for product improvements or efficiency enhancements by developing existing technologies further ([4]; [23]).

- Information Distribution is perceived as motivating if the input can be utilized and help to improve a company's situation [38].

- Documentation of Personal Contents is strongly related to Information Distribution. But besides from reusing own ideas, the fact that own ideas are conserved somewhere is perceived as motivating [38].

- Improved Human Capital or in other words having a learn success is per se a motivational factor [43]. 
- Immaterial Reward has to be distinguished from Direct Compensation. An immaterial reward is perceived, when the reputation of a company is gained [6].

- Competition per se is motivating for participants in Open Innovation projects. Not the price, but the chance to win the competition is essential [35].

- Reputation is according to [34] part of our basic needs. The increase of one's own status in a group or community has a positive effect on one's motivation ([41]; [6]).

- Communication Possibility: Meeting and working together with likeminded people is another motivation encouraging factor. This becomes especially obvious in online communities or forums. Further, working together with experts is also perceived as motivating [41].

The importance of each factor is depending on the company's individual situation. Factors such as OI-methods or -partners need to be considered for making a decision which factors need to be considered during the planning of an OIproject [28]. Not every motivational factor as described before can be fully satisfied at the same time because certain circumstances do not allow fulfilling every single motivational factor. For example, competition can be perceived as motivating, but during a Lead-User-Workshop the Lead-User should work together to find a common solution. Thus, motivational factors that are relevant for a specific OI-project have to be identified during the planning of an OI-project. On this basis, appropriate measures to indicate these factors have to be derived. For both, the identification of relevant motivational factors as well as the derivation of appropriate measures to indicate them, structured methodologies and applicable tools are missing.

\section{III.METHODOLOGY FOR IDENTIFYING APPROPRIATE MEASURES TO MOTIVATE EXTERNAL OI-PARTNERS}

In order to answer the research questions mentioned above under consideration of the current state of the art, a methodology was developed, which consists of three steps (see Fig. 5).

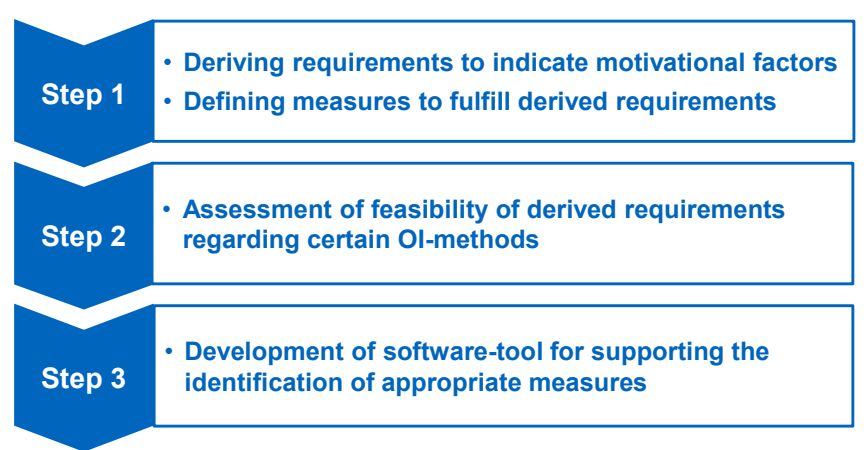

Fig. 5 Methodology for identifying appropriate measures to motivate external OI-partners

\section{A. Requirements to indicate motivational factors and measures to fulfill them}

At the beginning of step one all motivational factors with nearly the same meaning like "Self-Marketing" and "Reputation" are consolidated as far as possible in order to prevent redundancies. Subsequently, it is necessary to derive respective requirements to indicate the (consolidated) motivational factors within a specific OI-project. On this basis, appropriate measures to fulfill derived requirements have to be defined at the end of step one. Those measures mainly base on research activities of [12], [41], [23], [26] and $[42]$ in the field of motivation and OI. At this point all measures are described generically to ensure their transferability to various industrial contexts. The results are documented in Table I.

TABLE I (PART 1 OF 2)

OVERVIEW OF MOTIVATIONAL FACTORS AND RELATED MEASURES TO INDICATE THEM

\begin{tabular}{|c|l|l|}
\hline $\begin{array}{c}\text { Motivational } \\
\text { Factors }\end{array}$ & \multicolumn{1}{|c|}{$\begin{array}{c}\text { Requirements to Indicate } \\
\text { Motivational Factor }\end{array}$} & \multicolumn{1}{c|}{ Measure to Fulfil Requirements } \\
\hline $\begin{array}{c}\text { Enjoying the task/ } \\
\text { flow experience }\end{array}$ & $\begin{array}{l}\text { Satisfying tasks suit capabilities } \\
\text { of external OI-partners } \\
\text { Feedback between company and } \\
\text { external OI-partner }\end{array}$ & $\begin{array}{l}\text { Tasks should have different levels of difficulty and contents. If these are } \\
\text { aligned to the skills of each external partner, the task will be perceived } \\
\text { as more attractive. Additionally it should be considered, that feedback is } \\
\text { possible in both directions. }\end{array}$ \\
\hline $\begin{array}{c}\text { Team objectives } \\
\text { Self-marketing/ } \\
\text { reputation }\end{array}$ & $\bullet \begin{array}{l}\text { Team work among external OI- } \\
\text { partners }\end{array}$ & $\begin{array}{l}\text { It is recommendable that task should be designed in a way, that } \\
\text { teamwork is allowed. }\end{array}$ \\
\hline $\begin{array}{c}\text { Self-efficacy/ } \\
\text { Learning Success } \\
\text { contribution }\end{array}$ & $\bullet \begin{array}{l}\text { Facilitation of learning success of } \\
\text { external OI-partners }\end{array}$ & $\begin{array}{l}\text { Most valuable (outstanding) contributions of external OI-partners should } \\
\text { be promoted and highlighted adequately. }\end{array}$ \\
\hline $\begin{array}{l}\text { The task should challenge the skills of participants and allow to extent } \\
\text { their knowledge after participating. Personal capabilities of OI-partners } \\
\text { should be considered in the beginning and extended over the OI-project. } \\
\text { Feedback loops facilitate the achievement. }\end{array}$ \\
\hline Expected Profit
\end{tabular}


TABLE II (PART 2 OF 2)

OVERVIEW OF MOTIVATIONAL FACTORS AND RELATED MEASURES TO INDICATE THEM

\begin{tabular}{|c|l|l|}
\hline $\begin{array}{c}\text { Motivational } \\
\text { Factors }\end{array}$ & $\begin{array}{c}\text { Requirements to Indicate } \\
\text { Motivational Factor }\end{array}$ & \multicolumn{1}{c|}{ Measures to Fulfil Requirements } \\
\hline $\begin{array}{c}\text { Importance for } \\
\text { project/ immaterial } \\
\text { reward }\end{array}$ & $\begin{array}{l}\text { Assignment of key role to } \\
\text { external OI-partners }\end{array}$ & $\begin{array}{l}\text { The OI-project should be designed in a way that each external OI- } \\
\text { partner has a key role within the OI-project. }\end{array}$ \\
\hline $\begin{array}{c}\text { Technology } \\
\text { Improvement }\end{array}$ & $\begin{array}{l}\text { Attraction of interest in } \\
\text { technology }\end{array}$ & $\begin{array}{l}\text { The interest to improve a technology and the contribution to the OI- } \\
\text { project's success should be obvious right from the beginning. }\end{array}$ \\
\hline $\begin{array}{c}\text { Information } \\
\text { Distribution \& } \\
\text { Documentation }\end{array}$ & $\bullet$ Access to personal contributions & $\begin{array}{l}\text { Contributions of external OI-partners should be documented and } \\
\text { accessible for other external OI-partners and companies which can } \\
\text { potentially use the input. }\end{array}$ \\
\hline $\begin{array}{c}\text { Competition } \\
\text { Communication } \\
\text { Possibility }\end{array}$ & $\begin{array}{l}\text { Competition between external OI- } \\
\text { partners }\end{array}$ & $\begin{array}{l}\text { The possible outcome should be attractive and the winners should be } \\
\text { published afterwards. }\end{array}$ \\
\hline $\begin{array}{l}\text { Contact between external OI- } \\
\text { partners and company } \\
\text { pontact between external OI- }\end{array}$ & $\begin{array}{l}\text { The OI-project should allow communication within external OI-partners } \\
\text { as well as with experts of a company. }\end{array}$ \\
\hline
\end{tabular}

B. Open Innovation-method specific assessment of feasibility of derived requirements

After deriving appropriate requirements in order to indicate motivational factors, it is important to identify which requirement can be fulfilled for which OI-method as all of them are aiming at different objectives. In the following, the results for all OI-methods presented in chapter II (A. Open Innovation Methods) are listed separately.

- Idea Competitions:

- Feedback from company to external OI-partners: It is the nature of a competition not giving any feedback during the participation period, but only at the end. The requirement can be fulfilled.

- Feedback between external OI-partners: Ideas of each external OI-partner are accessible and therefore an evaluation of peers is realizable for an Idea Competition. The requirement can be fulfilled.

- Team work among external OI-partners: Every participant has to come up with own ideas. Therefore, team work is not allowed within this method. The requirement cannot be fulfilled.

- Publication of most valuable contributions: At the end of a competition the winners are nominated - the requirement can be fulfilled.

- Facilitation of learning success of external OIpartners: For an Idea Competition already acquired skills have to be applied, but they are not extended during an Idea Competition. Thus, this requirement cannot be fulfilled.

- Attractive outcome prospects: The incentive for an Idea Competition is per se having the best ideas and be rewarded. The requirement can be fulfilled.

- No restriction of solution space: The external OIpartner submits his suggestion which is then evaluated by the company. The solution space is therefore not limited and the requirement can be fulfilled.

- Assignment of key role to external OI-partners: Every opinion in an Idea Competition is to be evaluated equally. Therefore, every participant has a key role in an Idea Competition. The requirement can be fulfilled.
- Attraction of interest in technology: A requirement to take part in the competition, that the product is at least known to the consumer. However, developing a technology can be seen as subordinate. The requirement can be fulfilled.

- Access to contributions: In the course of Idea Competitions the winner and responding ideas are made public at the end. The requirement can be fulfilled.

- Competition between external OI-partners: This requirement is automatically fulfilled by the character of the OI-method.

- Contact between external OI-partners and company: External OI-partners submit their ideas but direct contact to the company is not provided during the Idea Competition. The requirement cannot be fulfilled.

- Contact between external OI-partners: Ideas of each external OI-partner are accessible and therefore an exchange of peers is essentially possible. The requirement can be fulfilled.

- Idea Platforms and Toolkits address the same objectives and are thus listed together:

- Feedback from company to external OI-partners: A company has a moderating function within an Idea Platform/ Toolkit, whereas the feedback from the company is an essential part of an Idea Platform/ Toolkit. The requirement can be fulfilled.

- Feedback between external OI-partners: On an Idea Platform/ Toolkit external OI-partners can submit their ideas and all other external OI-Partners can comment them. The requirement can be fulfilled.

- Team work among external OI-partners: Idea platforms/ Toolkits are designed in order to facilitate collaboration among external OI-partners. The requirement can be fulfilled.

- Publication of most valuable contributions: The publication of the most promising ideas and contributions is not common on an Idea Platform/ Toolkit. The requirement cannot be fulfilled. 
○ Facilitation of learning success of external OIpartners: As external OI-partners interact on the Idea Platform/ Toolkit, they can benefit from each other and a learning success can be achieved. The requirement can be fulfilled.

- Attractive outcome prospects: The most rewarding outcome is that the contributed idea is implemented and launched in the market. Therefore an attractive outcome is provided. The requirement can be fulfilled.

○ No restriction of solution space: The external OIpartner submits his suggestion which is then evaluated by the company. The solution space is therefore not limited and the requirement can be fulfilled.

○ Assignment of key role to external OI-partners: Every contribution on an Idea Platform/ Toolkit is to be evaluated equally. Therefore, every external OI-partner has a key role. The requirement can be fulfilled.

○ Attraction of interest in technology: A prerequisite to be part of an Idea Platform/ Toolkit is the interest in a technology. The requirement can be fulfilled.

- Access to contributions: The ideas contributed on an Idea Platform/ Toolkit are published online. The requirement can be fulfilled.

- Competition between external OI-partners: As the aim is to develop jointly a product and collect the ideas for a product innovation, competition is achieved within this method. The requirement can be fulfilled.

- Contact between external OI-partners and company: Companies are part of the Idea Platform/ Toolkit. If questions arise, the company can intervene respectively. The requirement can be fulfilled.

- Contact between external OI-partners: Idea Platforms/ Toolkits are designed in order to facilitate collaboration among external OI-partners. The requirement can be fulfilled.

- Problem-Broadcasting:

○ Feedback from company to external OI-partners: Except from sending answers to the question asked, feedback is not provided from the company to the external OI-partner during the Problem-Broadcasting. The requirement cannot be fulfilled.

○ Feedback between external OI-partners: Feedback between external OI-partner is not possible, as only the responsible company has access to the contributions of the external OI-partners. The requirement cannot be fulfilled.

○ Team work among external OI-partners: As problems are individually sent to the company by external OIpartners, team work is not achieved. The requirement cannot be fulfilled.

○ Publication of most valuable contributions: For Problem-Broadcasting there is no publication of valuable contributions possible. The requirement cannot be fulfilled.

- Facilitation of learning success of external OIpartners: As external OI-partners only submit their contributions, there is no learning process possible for them. The requirement cannot be fulfilled.

- Attractive outcome prospects: A promising outcome is presented for external OI-partners. The requirement can be fulfilled.

○ No restriction of solution space: Companies do not limit the space of creativity within a ProblemBroadcasting. The requirement can be fulfilled.

- Assignment of key role to external OI-partners: Every contribution in the Problem-Broadcasting method is to be evaluated equally. Therefore, every external OIpartner has a key role. The requirement can be fulfilled.

- Attraction of interest in technology: A prerequisite to be part of Problem-Broadcasting is to be already a product user. The requirement can be fulfilled.

- Access to contributions: The contributions are submitted to the companies and therefore not accessible for external OI-partners. The requirement cannot be fulfilled.

- Competition between external OI-partners: A low manifestation of competition is perceived but there are no specifically defined winning criteria. The requirement can be fulfilled.

- Contact between external OI-partners and company: Communication between the external OI-partners and responsible companies is not designated during the submitting of contributions. The requirement cannot be fulfilled.

- Contact between external OI-partners: For the Problem-Broadcasting approach communication between external OI-partners is not allowed. The requirement can be fulfilled.

- Communities for OI:

○ Feedback from company to external OI-partners: External OI-partners discuss certain topics among each other while the company is not explicitly meant to participate in this discussion. The requirement cannot be fulfilled.

○ Feedback between external OI-partners: External OIpartners discuss their individual ideas in this community. The requirement can be fulfilled.

○ Team work among external OI-partners: By discussing within the community the external OIpartners support each other and achieve solutions by cooperation. The requirement can be fulfilled.

○ Publication of valuable contribution: To be able to publish the winner's name, a winner has to be identified. As this is clearly not the case, the requirement cannot be fulfilled.

○ Facilitation of learning success of external OIpartners: The basic idea of Communities for OI is to exchange opinions and ideas. Therefore, besides the application of own knowledge, the potential for knowledge extension is provided. The requirement can be fulfilled. 
- Attractive outcome prospects: The participation in a Community for OI is not incentivised by attractive prices. The motivation has to be intrinsic, while e.g. by being selected as a unique participant. The requirement cannot be fulfilled.

○ No restriction of solution space: The solution space is not limited by the company. Every external OI-partner might discuss their individual idea within the community. The requirement can be fulfilled.

○ Assignment of key role to external OI-partners: Every opinion within a Community for OI is to be evaluated equally. Therefore, every external OI-partner has a kind of a key role. The requirement can be fulfilled.

○ Attraction of interest in technology: Being part of a community is everybody's own choice. A prerequisite for participation is therefore the interest in the topic or technology. The requirement can be fulfilled.

- Access to contributions: Within the community ideas are documented and accessible for other external OIpartner. The requirement can be fulfilled.

- Competition between external OI-partners: Ideas are discussed within the community. External OI-partners attempt to cooperate in finding a solution. Thus, no competitive characteristics are determined. The requirement cannot be fulfilled.

- Contact between external OI-partners and company: Companies initiating a Community for OI also takes part in the discussions. The requirement can be fulfilled.

- Contact between external OI-partners: By discussing within the community the external OI-partners get in contact. The requirement can be fulfilled.

- Lead-User-Workshop:

○ Feedback from company to external OI-partners: Companies are able to directly give feedback within the Lead-User-Workshop. The requirement can be fulfilled.

○ Feedback between external OI-partners: Within a Lead-User-Workshop the possibility to exchange ideas is provided. The requirement can be fulfilled.

○ Team work among external OI-partners: By means of discussion in the workshop Lead-User are supporting each other and are able to define solutions in cooperative teams. The requirement can be fulfilled.

- Publication of valuable contribution: To be able to publicize the winner and his corresponding solution, a winner has to be defined. As this is not the case, the requirement cannot be fulfilled.

- Facilitation of learning success of external OIpartners: Lead-Users are not only selected within an industry, but also identified in other areas. It is therefore possible to transfer best practice solutions from another industry, which implies that the different areas can benefit from each other. The requirement can be fulfilled.
- Attractive outcome prospects: The underlying concept is not associated to competition, but the Lead-User have to be motivated intrinsically. The requirement cannot be fulfilled.

○ No restriction of solution space: The solution space is basically not limited by the company. The requirement can be fulfilled.

- Assignment of key role to external OI-partners: Selecting Lead-Users for this OI-method is a crucial step for the method's success. Therefore, every person within the workshop have to be conveyed the essence of his contributions. The requirement can be fulfilled.

- Attraction of interest in technology: Lead-Users can be distinguished from others by seeking for progressiveness in terms of product requirements. Therefore, existing solutions do not fulfil their needs, for what reason they are interested in improving the technology. The requirement can be fulfilled.

- Access to contributions: The method does not enable Lead-Users to review the respective contributions at a later point in time. The requirement cannot be fulfilled.

- Competition between external OI-partners: The objective of a Lead-User-Workshop is to work collaboratively on a solution which yet not found in the market. Therefore, competition is not inherent in this OI-method. The requirement cannot be fulfilled.

- Contact between external OI-partners and company: Lead-Users are invited by the responsible company and in doing so contact to the company is established. The requirement can be fulfilled.

- Contact between external OI-partners: For a LeadUser-Workshop not only one Lead-User is invited, but the aim is to invite the most progressive ones. Therefore, within the workshop, the contact between Lead-Users is provided. The requirement can be fulfilled.

- Immersive Product Improvement (IPI):

○ Feedback from company to external OI-partners: Companies might give feedback directly by means of commenting the suggestions of external OI-partners. The requirement can be fulfilled.

○ Feedback between external OI-partners: The underlying concept is to discuss or leave comments on a product by clicking on product components and starting with new comments or answering to predecessors. The requirement can be fulfilled.

○ Team work among external OI-partners: However, comments of external OI-partners can be accessed by other external OI-partners collaborative working is not provided within this method. The requirement cannot be fulfilled.

- Publication of valuable contribution: To be able to give honour to outstanding external OI-partners, there have to be a competitive component based on certain criteria. This not achieved in this method and thus, the requirement cannot be fulfilled. 
○ Facilitation of learning success of external OIpartners: By giving the possibility to answer on comments of other external OI-partners, it is possible to gain knowledge. For example, as some aspects would have not been considered by oneself, but by other external OI-partners. The requirement can be fulfilled.

- Attractive outcome prospects: There is no material or immaterial incentive, which is promised to the external OI-partners. The requirement cannot be fulfilled.

○ No restriction of solution space: The solution space is limited by the company as the external OI-partners are offered a defined solution space to operate within. If a certain component is not existent yet, it cannot be clicked on it. The method is thus only feasible to improve the component of a product already existent. The requirement cannot be fulfilled.

○ Assignment of key role to external OI-partners: In selecting the external OI-partners to participate in IPI certain selection criteria have to be applied. Therefore the requirement is fulfilled.

○ Attraction of interest in technology: One part of the selection criteria of the external OI-partners to identify those, who have an interest in this certain technology. The requirement can be fulfilled.

- Access to contributions: The method enables the external OI-partners to access and review contributions of other external OI-partners. The requirement can be fulfilled.

- Competition between external OI-partners: There is no competitive character inherent in this method. The requirement cannot be fulfilled.

- Contact between external OI-partners and company: An interaction of external OI-partners and companies is part of this method. The requirement can be fulfilled.

- Contact between external OI-partners: An interaction between external OI-partners is a fundamental part of this method. The requirement can be fulfilled.

- University Cooperation \& Cross-Industry Workshops fulfil the same requirements according to [44] and are thus listed together:

○ Feedback from company to external OI-partners: The exchange of information within cooperation is mostly implemented directly between the departments. Therefore direct feedback is facilitated and the requirement can be fulfilled.

○ Feedback between external OI-partners: As direct feedback between companies is feasible within cooperation and also within the department, the requirement is generally fulfilled both within and outside the company, e.g. in case of a consortium.

○ Team work among external OI-partners: Implied by the collaboration of respective departments a team is formed working collaboratively on the OI-project. The requirement can be fulfilled.

- Publication of valuable contribution: In order to name outstanding performers a competitive character has to be provided. But this is not fulfilled. Therefore, the requirement cannot be fulfilled.

- Facilitation of learning success of external OIpartners: By agreeing on collaboration the expertise of all parties are part of the OI-project. By bringing different disciplines or research results together, the chance of expanding the own knowledge base is provided. The requirement can be fulfilled.

- Attractive outcome prospects: The collaboration is not incentivised by paying each partner a certain collaboration fee. However, in advance an agreement on possible innovation outcomes should be considered. The requirement can be fulfilled.

○ No restriction of solution space: At universities the solution space is usually more open as within companies, but still not unlimited. The defined targets of the project shall be achieved. The requirement cannot be fulfilled.

○ Assignment of key role to external OI-partners: By having collaboration agreement only with the ones crucial for the OI-project success the requirement is generally fulfilled.

- Attraction of interest in technology: A collaboration of organizations is only then possible when there is the shared interest of a certain technology. The requirement can be fulfilled.

○ Access to contributions: According to quality management regulations a transparent documentation of work is necessary for collaborations. As these regulations are common business practices the requirement can be fulfilled for both companies and universities.

- Competition between external OI-partners: There is not a competitive character inherent in this method. The requirement cannot be fulfilled.

- Contact between external OI-partners and company: An interaction between external OI-partners and companies is part of this method. The requirement can be fulfilled.

- Contact between external OI-partners: An interaction between external OI-partners is part of this method. The requirement can be fulfilled.

C. Excel-based software-tool for supporting the identification of approriate measures

An essential aim of the methodology is to support the identification of appropriate measures for motivating external OI-partners by an interactive software-tool in order to ensure a maximum degree of usability. Based on the OI-method to be selected by the company, an overview of the motivational factors, respective requirements to be fulfilled and allocated, appropriate measures are provided. This approach is based on the findings provided in step 1 and 2 of the methodology presented in this chapter. In order to guarantee the application of the generic measures, a detailed example is provided for each measure, which gives suggestions on how a certain measure can be realized depending on the specific OI-method. 
Identifying Measures to Motivate External Ol-Partners

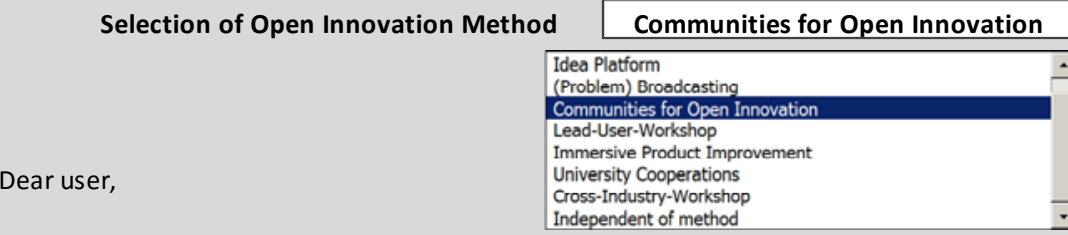

Please select here!

the aim of this tools is to identify appropriate measures to motivate external Open Innovation-partners. As different Open Innovation-methods require different motivational factors, this tool provides guidance to identify the measures depending on the selected Open Innovation-method.

Instruction:

Please select in the "white cell" the Open Innovation-method you want to use for your Open Innovation-project. After that you will receive the motivational factors for the selected Open Innovation-method. Select the sheet "Incentive and Implementation" or "Examples for Implementation" in order to get the desired information.

Fig. 6 Screenshot of "Landing Page" of the interactive Excel-based software-tool

\begin{tabular}{|c|c|c|}
\hline Selected OI-Method: & "Communities for Open Innovation" & \\
\hline Motivational Factor & Requirement & Measure \\
\hline $\begin{array}{l}\text { Enjoying the task / } \\
\text { Flow experience }\end{array}$ & $\begin{array}{l}\text { 1) Satisfying tasks suit capabilities of } \\
\text { external OI-partners } \\
\text { 2) Feedback between company and external } \\
\text { OI-partner }\end{array}$ & $\begin{array}{l}\text { 1) Tasks should have different levels of } \\
\text { difficulty and contents. If these are } \\
\text { aligned to the skills of each external } \\
\text { partner, the task will be perceived as } \\
\text { more attractive. } \\
\text { 2) Additionally it should be considered, that } \\
\text { feedback is possible in both directions. }\end{array}$ \\
\hline Team objectives & 1) Team work among external OI-partners & $\begin{array}{l}\text { 1) It is recommendable that task should be } \\
\text { designed in a way, that teamwork is } \\
\text { allowed. }\end{array}$ \\
\hline $\begin{array}{l}\text { Self-marketing / } \\
\text { Reputation }\end{array}$ & 1) Publication of most valuable contribution & $\begin{array}{l}\text { 1) Most valuable (outstanding) } \\
\text { contributions of external Ol-partners } \\
\text { should be promoted and highlighted } \\
\text { adequately. }\end{array}$ \\
\hline \begin{tabular}{|l|}
$\begin{array}{l}\text { Compensation / } \\
\text { Expected Profit }\end{array}$ \\
\end{tabular} & N/A & $\mathrm{N} / \mathrm{A}$ \\
\hline$\ldots$ & $\ldots$ & \\
\hline
\end{tabular}

Fig. 7 Screenshot of the "Incentives Page" (extract) of the interactive Excel-based software-tool

When a company is planning an OI-project, it has first of all to select an appropriate OI-method as well as suitable external OI-partner to conduct this. For selecting an appropriate OI-method, the overall objective of the OI-project should be considered primarily. Subsequently, the interactive software-tool can be consulted for identifying suitable measures to motivate the selected, external OI-partners. For example, a company is aiming to do create a "Community for OI" the respective OI-method has to be selected on the "Landing Page" of the interactive software-tool (see Fig. 6). Then the measures to motivate external OI-partners within a "Community of OI" are displayed on the "Incentive Page" (see Fig. 7). By this, the user of the interactive software-tool finds all desired information. For example, it is important to provide different levels of difficulties concerning the task presented to the community to be sure that every external OIpartner who is participating can enjoy the task and get a flow experience which results in a high degree of motivation.

\section{REFLECTION AND OUTLOOK}

The methodology presented in this paper provides a structured identification of suitable measures to motivate external OI-partners regarding a specific OI-project. The adaption of the methodology to a specific OI-project is enabled by the developed, generic data base of possible motivation measures and their allocation to existing OImethods. Furthermore, the methodology enables the identification of additional motivational factors as well as the derivation of respective requirements and measures for their realization. Thereby, the data base of measures can be individually expanded as desired. The developed, interactive software-tool supports the usage of the methodology, means identifying suitable measures for motivating external OIpartners. After selecting the desired OI-method, an automatically generated listing (based on the developed data base of measures) of motivational factors that need to be 
observed as well as requirements and measures for their realization. The user of the software-tool is thereby in a position to identify suitable motivation measures without having detailed knowledge about the application of the methodology.

To what extend the methodology and the interactive software-tool indeed contribute to increase the motivation of external OI-partners has to be investigated by an evaluation. For significant statements, this evaluation should be executed on the basis of various companies of different industries. Furthermore, the influence of the widely differing, external OI-partners on the success of identified motivational measures should be investigated. In case of an influence, an additional allocation of motivational measures to generic groups of possible, external OI-partners would be necessary. Indications for the definition of those groups are already provided in the presented paper.

\section{REFERENCES}

[1] O. Alexy, M. Leitner, "Norms, rewards, and their effect on the motivation of open source software developers", Working Paper, Technical University of Munich, 2008.

[2] F. Belz, F. W. Baumbach, "Netnography as method of lead user identification“, Creativity and Innovation Management, pp. 304 - 313, 2010.

[3] L. T. M. Blessing, A. Chakrabarti, "DRM, a Design Research Methodology", Heidelberg: Springer, 2009.

[4] A. Bonaccorsi, C. Rossi Lamastra, S. Giannangeli, "Adaptive Entry Strategies Under Dominant Standards-Hybrid Business Models in the Open Source Software Industry“, 2004.

[5] A. Braun, "Open Innovation - Einführung in ein Forschungsparadigma“, In: A. Braun, E. Eppinger, G. Vladova, S. Adelhelm, "Open Innovation in Life Sciences", Gabler, pp. 3-24, 2012.

[6] U. Bretschneider, "Motivation for Participation in Ideas Competitions: Empirical Insights from the SAPiens Case", In: H. Arndt et al., "Very Large Business Applications (VLBA)“, Shaker, pp. 124-138, 2009.

[7] E. Chatenier, J. Verstegen, H. Biemans, M. Mulder, O. Omta, "Identification of competencies for professionals in open innovation teams.“ R\&D Management, Vol. 40, No. 3, p. 271-280, 2010.

[8] H. W. Chesbrough, "Open Innovation: A new Paradigm for Understanding Industrial Innovation", In: H. W. Chesbrough, W. Vanhaverbeke, J. West (Hrsg.), "Open Innovation - Researching a new Paradigm". Oxford: University Press, pp. 1-12, 2006.

[9] H. W. Chesbrough, W. Vanhaverbeke, J. West, "Open innovation: Researching a new paradigm", Oxford University Press, 2006.

[10] C. Christensen, "The innovator's dilemma: when new technologies cause great firms to fail“", Harvard Business Review Press, 2013.

[11] C. Crawford, C. Di Benedetto, "New products management", Tata McGraw-Hill Education, 2008.

[12] M. Csikszentmihalyi, "Flow and the Psychology of Discovery and Invention“, HarperPerennial, Vol. 39, 1997.

[13] K. Diener. F. Piller, "Methoden und Dienstleister für die OIImplementation". In: S. Ili (Hrsg.), "Open Innovation umsetzen Prozesse, Methoden, Systeme, Kultur", Symposion Publishing, 2010.

[14] W. Ebner, J. Leimeister, H. Krcmar, "Community engineering for innovations: the ideas competition as a method to nurture a virtual community for innovations“, R\&D Management, Vol. 39, No. 4, pp. 342-356, 2009.

[15] M. Elmquist, T. Fredberg, S. Ollila, "Exploring the field of open innovation", European Journal of Innovation Management, Vol. 12, Iss. 3, pp. 326-345, 2009.

[16] E. Enkel, C. Dürmüller, "Cross-Industrie Innovationen: Der Blick über den Gartenzaun", Praxiswissen Innovationsmanagement, 2008.
[17] E. Enkel, O. Gassmann, "Creative imitation: exploring the case of cross-industry innovation". R\&D Management, 40(3), pp. 256-270, 2010.

[18] E. Gourova, K. Toteva, "Raising creativity and participation in innovation and knowledge management activities," In: K.-D. Thoben, V. Stich, A. Imtiaz (Hrsg.), Proceedings of the 17th International Conference on Concurrent Enterprising, 2011.

[19] M. R. Guertler, M. Holle, D. Guber, U. Lindemann, "Open Innovation: Industrial Application and Demands - a Qualitative Study", R\&D Management Conference, Stuttgart, 2014.

[20] M. R. Guertler, U. Lindemann, "Situative Open Innovation - A model for selecting the right external actors and involving them in an efficient way", In: U. Lindemann, S. Venkataraman, Y. S. Kim, S. W. Lee (eds.), Proceedings of the 19th International Conference on Engineering Design, Vol. 3: Design Organisation and Management,Seoul, Korea 2013.

[21] M. R. Guertler, C. von Saucken, M. Schneider, U. Lindemann, "How to search for Open Innovation partners?", Proceedings of International Conference on Engineering Design, Milano, Italy, 2015.

[22] A. Hars, S. Ou, "Working for Free? Motivations of participating in Open Source projects", International Journal of Electronic Commerce, Vol. 6, pp. 25-39, 2002.

[23] G. Hertel, S. Niedner, S. Herrmann, "Motivation of software developers in open source projects: an internet-based survey of contributions to the linux kernel“", Research Policy, Vol. 32, Iss. 7, pp. 1159-1177, 2003.

[24] E. K. R. E. Huizingh, "Open innovation: State of the art and future perspectives", Technovation, 31(1), pp. 2-9, 2010.

[25] S. Ili, A. Albers, "Chancen und Risiken von Open Innovation", In: Ili, S. (Hrsg.) "Open Innovation umsetzen: Prozesse, Methoden, Systeme, Kultur“, Düsseldorf, 2010.

[26] H. Kehr, "Das Kompensationsmodell der Motivation und Volition als Basis für die Führung von Mitarbeitern", In: R. Vollmeyer, J. C. Brunstein, "Motivationspsychologie und ihre Anwendung", pp. 131$150,2005$.

[27] M. Keupp, O. Gassmann, "Determinants and archetype users of open innovation“, R\&D Management, Vol. 39, no 4, p. 331-341, 2009.

[28] R. Kirschner, "Methodische offene Produktentwicklung", Institute of Product Development, Technical University Munich, 2012.

[29] R. Kirschner, A. Kain, A. Lang, U. Lindemann, "Immersive Product Improvement IPI - First empirical Results of a new Method“, Proceedings of the 18th International Conference on Engineering Design, Impacting Society through Engineering Design, Vol. 9: Design Methods and Tools pt. 1, Lyngby/Copenhagen, Denmark, 2011.

[30] K. R. Lakhani, E. von Hippel, "How open source software works: "free" user-to-user assistance", Research Policy 32, pp. 923-943, 2002.

[31] K. Lakhani, R. Wolf, "Why hackers do what they do: Unterstanding motivation and efforts in free/open source software projects", In: J. Feller et al., "Perspectives on Free and Open Source Software", Cambridge, 2005.

[32] K. Lewin, "Action research and minority problems", In Journal of Social Issues, Vol. 4, pp. 34-46, 1946.

[33] C. Lüthje, "Kundenorientierung im Innovationsprozess: Eine Untersuchung der Kunden-Hersteller-Interaktion in Konsumgütermärkten“, Gabler, 2000.

[34] D. McClelland, R. Koestner, J. Weinberger, "How do Self-Attributed and Implicit Motives Differ?", Psychological Review, Vol. 96, pp. 690702, 1989.

[35] R. Reichwald, F. Piller, "Interaktive Wertschöpfung: Open Innovation, Individualisierung und neue Formen der Arbeitsteilung", Gabler, 2009.

[36] K. Schattke, H. Kehr, "Motivation zur Open Innovation". In: A. Zerfaß, K. Möslein, "Kommunikation als Erfolgsfaktor im Innovationsmanagement: Strategien Im Zeitalter der Open Innovation“, Gabler, 2009.

[37] S. Silvertant, "Ideenwettbewerbe als Methode zur Ideengenerierung und Identifikation potenzieller Lead User im Kontext schnelllebiger Konsumgüter", 2011.

[38] R. Stöckl, P. Rohrmeier, T. Hess, "Why Customers Produce User Generated Content", In: B. Hass, G. Walsh, T. Kilian, "Web 2.0", Springer, 2007. 
[39] P. Trott, "Innovation Management and New Product Development", University of Portsmouth Business School and Delf University of Technology, 2008.

[40] D. Vahs, A. Brem, "Innovationsmanagement - Von der Idee zur erfolgreichen Vermarktung", 4. Ausg., 2013.

[41] D. Walcher, "Der Ideenwettbewerb als Methode der Open Innovation", In: A. Zerfaß, K. Möslein, "Kommunikation als Erfolgsfaktor im Innovationsmanagement“, pp. 141-157, Gabler, 2009.
[42] J. E. Wenger, "Gewinngestaltung bei Innovationswettbewerben Theoretische und praktische Betrachtung", Wiesbaden: Gabler, 2013.

[43] C. Wu, J. Gerlach, C. Young, "An empirical analysis of open source software developers' motivations and continuance intentions", Information \& Management, Vol. 44, Iss. 3, pp.253-262, 2007. 